\title{
Evaluation of Variation in Time of Harvest Maturity of Flowering Shoots in Three Cultivars of Gentian
}

\author{
Uttara C. Samarakoon ${ }^{1,3}$, Keith A. Funnell ${ }^{1,2,4}$, David J. Woolley ${ }^{1}$, \\ and Edward R. Morgan ${ }^{2}$
}

AdDitional index words. cultivar differences, cut flower, growing degree-days, plant-to-plant variation, time to shoot emergence

SUMMARY. The time to harvest maturity of flowering shoots and the extent and source of variability in maturity dates differed among cultivars of gentian (Gentiana sp.), with a wider spread in time to harvest maturity in Showtime Starlet (41 days) than Showtime Diva (35 days) and Showtime Spotlight (29 days). Cultivars also differed by more than twice in their plant-to-plant variability in time to harvest. Although later-emerging shoots reached harvest maturity more quickly than earlieremerging shoots, the use of growing degree-days (GDD) for this field-grown cut flower did not account for differences. For 'Showtime Diva', 77\% of outliers reached harvest maturity at the beginning of the season (i.e., before the 10 th percentile). For 'Showtime Spotlight', only $\mathbf{2 0 \%}$ of shoots classified as outliers flowered early with the remaining $80 \%$ emerging late (i.e., after the 90th percentile). Strategies to control the spread in time to harvest maturity in late-maturing cultivars such as Showtime Starlet should focus on uniform shoot emergence and controlling temperature during growth. Although strategies to achieve uniform shoot emergence should also be targeted for 'Showtime Diva', controlling temperature during the growing season would not appear to offer significant control of the spread in time of harvesting floral shoots. However, in earlier-maturing cultivars such as Showtime Spotlight, strategies will primarily require a greater understanding of the factors influencing the variability in maturation of shoots within individual plants before, and after, emergence.

I

nterest in gentian as a cut flower is growing internationally, with Japan currently being the single largest producer and consumer. The different cultivars making up an outdoorgrown gentian crop can be variable when their flowering shoots mature and, additionally, can have a long harvest window. Anecdotally, the variation has been observed among cultivars, and among plants of the same cultivar. This variation in harvest maturity makes it difficult to schedule harvest

Financial support from the New Zealand Foundation for Research, Science and Technology (contract C02X0702); Plant and Food Research CORE funding (12058-"Fashionable Plants for the Ornamentals Industry"); and Massey University Doctoral Scholarship are gratefully acknowledged.

We thank Duncan Hedderley for his support with statistical analysis. We also thank Ben van Hooijdonk and Kevin Patterson for their comments on the manuscript.

${ }^{1}$ Institute of Agriculture and Environment, Massey University, Palmerston North, 4474, New Zealand

${ }^{2}$ The New Zealand Institute for Plant and Food Research Limited, Private Bag 11 600, Palmerston North, 4442, New Zealand

${ }^{3}$ Current address: Department of Horticulture, Clemson University, E-143 Poole Agriculture Center, Clemson, SC 29634

${ }^{4}$ Corresponding author. E-mail: usamara@clemson.edu. operations and target high-value markets. A further difficulty of the long window of flowering means there are periods when few shoots are at harvest maturity, so the economics of harvesting stems can sometimes be marginal. Existing information about the spread in time of harvest maturity for this crop is based on anecdotal observations, with no published information available. Hence it was considered useful to quantitatively describe variation in time to harvest maturity, both among and within cultivars, so as to identify potential opportunities to manipulate flowering time.

Gentian plants are winter dormant, sprouting in spring and growing through the summer period (Samarakoon et al., 2010). Flowering is observed to occur in summer to late fall with many floral shoots per plant.
During fall and winter the aboveground organs naturally senesce, with the plant bearing overwintering crown buds, which give rise to floral shoots in the next season.

A differential temperature response of flower development between early- and late-flowering gentian cultivars was postulated by Ohkawa (1983), with flowering of early cultivars promoted at $20-25{ }^{\circ} \mathrm{C}$, whereas late-flowering cultivars were delayed by this temperature range. Thus, although the effects of temperature have not been quantified, they are likely to have an influence on the time of harvest maturity of individual shoots.

Most research related to flowering in ornamental plants deals with the phenological event (e.g., average time to anthesis or harvest), whereas in commercial reality, the spread in timing of these events is also important. As illustrated with other crops, the time required to reach anthesis or harvest maturity can be described using chronological days, GDD, and/or phenological scales (Fisher et al., 1998; Funnell et al., 2003). The temperature response curve and parameters for calculation of GDD have not been defined for any gentian cultivars. Therefore, in the research presented here, the time to harvest and other related phenological events were analyzed based on calendar days and a GDD model that assumed a linear response curve and a base temperature of $0{ }^{\circ} \mathrm{C}$ (Arnold, 1959).

In this article we describe the spread in time of harvest maturity of three clonally propagated cultivars: Showtime Spotlight (Spotlight), Showtime Diva (Diva), and Showtime Starlet (Starlet), grown under field conditions in New Zealand. To identify possible sources of variation among and within cultivars, we analyzed spread in the time of harvest maturity and its correlation with shoot emergence.

\section{Materials and methods}

Clonally propagated plants of the cultivar Diva were established as a commercial crop during Spring 2004, with

\begin{tabular}{lllc}
\hline $\begin{array}{l}\text { Units } \\
\begin{array}{l}\text { To convert U.S. to SI, } \\
\text { multiply by }\end{array}\end{array}$ & U.S. unit & SI unit & $\begin{array}{l}\text { To convert SI to U.S., } \\
\text { multiply by }\end{array}$ \\
\hline 2.54 & inch $(\mathrm{es})$ & $\mathrm{cm}$ & 0.3937 \\
0.0450 & $\mathrm{kilocalorie}(\mathrm{s}) / \mathrm{ft}^{2}$ & $\mathrm{MJ} \cdot \mathrm{m}^{-2}$ & 22.2044 \\
33.9057 & $\mathrm{Oz} / \mathrm{yard}^{2}$ & $\mathrm{~g} \cdot \mathrm{m}^{-2}$ & 0.0295 \\
$\left({ }^{\circ} \mathrm{F}-32\right) \div 1.8$ & ${ }^{\circ} \mathrm{F}$ & ${ }^{\circ} \mathrm{C}$ & $\left({ }^{\circ} \mathrm{C} \times 1.8\right)+32$
\end{tabular}


Spotlight and Starlet established in Spring 2003. Five single-plant replicates, each producing 20 or more flowering shoots per year, were selected from established plots in an open field located at the New Zealand Institute for Plant and Food Research Limited [Palmerston North, New Zealand (lat. $40^{\circ} 37^{\prime}$ S, long. $175^{\circ} 60^{\prime} \mathrm{E}$ )]. The natural mineral soil within the open field production system was classified as Manawatu fine sandy loam (Massey University, n.d.). During cultivation fertilizers were applied each season in response to soil analysis, and typically comprised $15 \mathrm{~g} \cdot \mathrm{m}^{-2}$ of $14 \mathrm{~N}-$ $7 \mathrm{P}-14 \mathrm{~K}-7.6 \mathrm{~S}-5 \mathrm{Mg}-1 \mathrm{Fe}$, granular slow-release fertilizer (Slowenne; Valagro, Atessa, Italy); $2 \mathrm{~g} \cdot \mathrm{m}^{-2}$ of $12 \mathrm{~N}-5 \mathrm{P}-15 \mathrm{~K}-8 \mathrm{~S}$ granulated fertilizer (Balance Agri-Nutrients, Mount Maunganui, New Zealand), $2 \mathrm{~g} \cdot \mathrm{m}^{-2}$ of $21 \mathrm{~N}-1.8 \mathrm{P}-9 \mathrm{~K}-0.002 \mathrm{~B}-0.005 \mathrm{Cu}-$ $0.05 \mathrm{Fe}-0.010 \mathrm{Mn}-0.002 \mathrm{Mo}-0.002 \mathrm{Zn}$ granular controlled-release fertilizer (Sierrablen; Scotts, Heerlen, the Netherlands), and $1.5 \mathrm{~g} \cdot \mathrm{m}^{-2}$ of dolomite $(2 \mathrm{lCa}-10 \mathrm{Mg}$; Prebbles Seeds, Christchurch, New Zealand), $1.5 \mathrm{~g} \cdot \mathrm{m}^{-2}$ of gypsum (23Ca-18S; Winstone Gypsum, Auckland, NZ). During the course of the experiment, plants were grown in raised beds with irrigation supplied by drippers, so as to avoid water stress, and received natural sunlight. At this latitude, daylength and total solar radiation varied from $11 \mathrm{~h}$ $51 \mathrm{~min}$ and $12 \mathrm{MJ} \cdot \mathrm{m}^{-2} \cdot \mathrm{d}^{-1}$ in September to a maximum of $15 \mathrm{~h}$ and 33 $\mathrm{MJ} \cdot \mathrm{m}^{-2} \cdot \mathrm{d}^{-1}$ in December, before declining to a minimum of $9 \mathrm{~h} 16 \mathrm{~min}$ and $6 \mathrm{MJ} \cdot \mathrm{m}^{-2} \cdot \mathrm{d}^{-1}$ in June.

Data collection started on 10 Sept. 2007 when buds first emerged after overwintering, and continued until 30 June 2008 . Daily average air temperatures during this period were recorded (Fig. 1).

When a shoot reached $5 \mathrm{~cm}$ above the soil surface, it was considered emerged. The emergence of individual shoots on each plant was recorded monthly. As each shoot reached harvest maturity [i.e., top-most flower bud was not open but had developed color (Eason et al., 2004)], its length and date of harvest were recorded. Date of harvest and length of axillary shoots, which emerged from the proximal end of already developed flowering shoots before their harvest, were also recorded.

For each shoot, the date of shoot emergence $(a)$ and harvest maturity

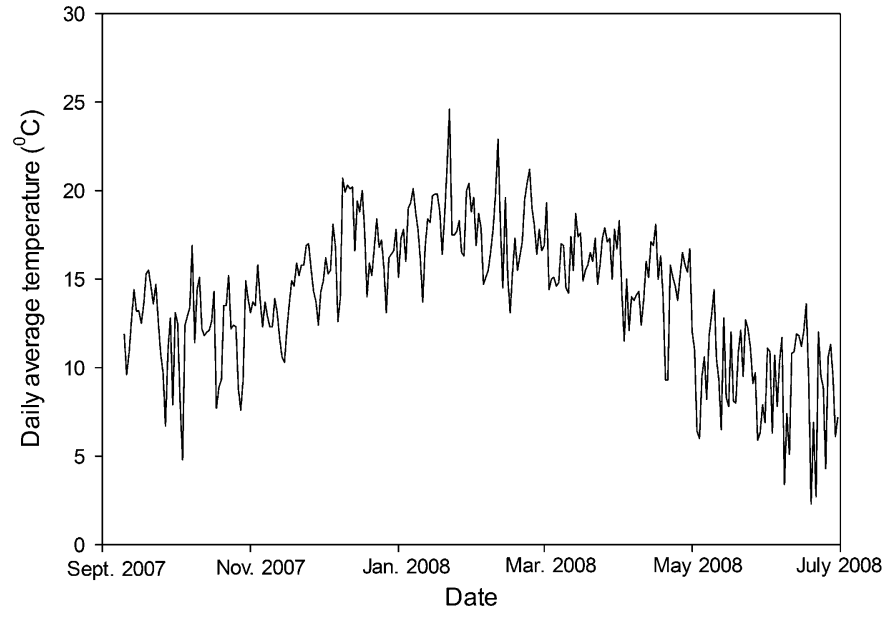

Fig. 1. Daily average temperature encountered in the open field at Palmerston North, New Zealand during Sept. 2007 to July 2008; $1.8 \times{ }^{\circ} \mathrm{C}+32={ }^{\circ} \mathrm{F}$.

(b) were recorded as calendar days. The time from emergence of the first shoot through to the emergence of subsequent shoots and harvest maturity, and the time from emergence of an individual shoot to harvest maturity of that shoot were determined as calendar days.

Times of emergence and harvest for each shoot were also calculated using a linear GDD model (Funnell, 2008 ) with a base temperature $\left(T_{\text {base }}\right)$ of $0{ }^{\circ} \mathrm{C}$. Daily maximum and minimum air temperatures were sourced from the AgResearch meteorological station (AgResearch, Palmerston North, New Zealand). Accumulated GDD from the date of emergence of the first shoot $(t)$ until attainment of each of the phenological stages of development ( $a$ and $b$ ) were calculated using Eq. [1]:

GDD =

$\sum_{t}^{a \rightarrow b}\left[\left(\begin{array}{l}\left(\begin{array}{c}\text { maximum temperature } \\ + \text { minimum temperature })\end{array}\right. \\ 2\end{array}\right)-\mathbf{T}_{\text {base }}\right]$

Data were analyzed using the general linear model's procedure and regression procedure in SAS (version 9.13; SAS Institute, Cary, NC). Mean comparisons were conducted using Tukey's test. Data were either normally distributed or approached normality to the extent that transformations did not alter the statistical outcome. Times to emergence and harvest, and from emergence to harvest, were analyzed using both calendar days and GDD.

Spread in time of harvest maturity among cultivars and within (i.e., among plants) were quantified with box and whisker plots in Sigma Plot (version 10.0; Systat Software, San Jose, CA) using data pertaining to multiple shoots within a plant. Together with the calculated mean values, the 10th, 25th, 50th (median), 75th, and 90th percentiles from the box and whiskers plots were used. Both standard deviation and the number of days representing the central $80 \%$ spread, as indicated by 10th to 90th percentile distribution in harvest maturity for each plant, were used to describe the spread in time of harvest maturity among and within cultivars. To determine the sources of variation within a cultivar, we separately analyzed data for shoots arising from each of the five individual plant replicates. Outliers present before the 10th and after the 90th percentile were used to describe the $20 \%$ of shoots available for harvest before and after the end of the commercial harvest season. The relationship between time to emergence and harvest maturity, using both calendar days and GDD, was evaluated using regression analysis within SAS.

\section{Results}

\section{Spread in time of harvest maturity among cultivars}

Distribution of time to HARVEST MATURITY. All shoots that emerged flowered. The average time from emergence of the first shoot (10 Sept. 2007) to harvest maturity differed among the cultivars (Table 1 ), with Spotlight maturing first, followed by Diva and then Starlet. The same sequence was observed with time from shoot emergence to harvest maturity, 
Table 1. Time to harvest maturity, shoot emergence, between emergence and harvest maturity, and both variation (SD) and spread in distribution in time (10th to 90 th percentile) for these parameters, for cultivars of gentian (Showtime Spotlight, Showtime Diva, and Showtime Starlet), as calendar days and growing degree-days [GDD base temperature $\left.0{ }^{\circ} \mathrm{C}\left(32.0{ }^{\circ} \mathrm{F}\right)\right]^{\circ}$

\begin{tabular}{|c|c|c|c|c|c|c|c|c|}
\hline Cultivar & $\begin{array}{l}\text { Time to } \\
\text { harvest } \\
\text { maturity }\end{array}$ & $\begin{array}{c}\text { Time to } \\
\text { emergence }\end{array}$ & $\begin{array}{l}\text { Time from } \\
\text { emergence } \\
\text { to harvest } \\
\text { maturity }\end{array}$ & $\begin{array}{l}\text { SD of time } \\
\text { to harvest } \\
\text { maturity }\end{array}$ & $\begin{array}{c}\text { SD of } \\
\text { time to } \\
\text { emergence }\end{array}$ & $\begin{array}{c}\text { SD of time } \\
\text { from emergence } \\
\text { to harvest maturity }\end{array}$ & $\begin{array}{l}\text { 10th to } 90 \text { th } \\
\text { percentile } \\
\text { distribution of } \\
\text { time to harvest } \\
\text { maturity }\end{array}$ & $\begin{array}{l}\text { 10th to } 90 \text { th } \\
\text { percentile } \\
\text { distribution } \\
\text { of time from } \\
\text { emergence } \\
\text { to harvest }\end{array}$ \\
\hline & \multicolumn{8}{|c|}{ (d) } \\
\hline Spotlight & $192 c^{* * * z}$ & $34 \mathrm{a} * * *$ & $157 c^{* * *}$ & $13 a^{\mathrm{NS}}$ & $18 b^{* *}$ & $14 b^{* *}$ & $29 \mathrm{~b}^{* *}$ & $36 b^{*}$ \\
\hline \multicolumn{9}{|c|}{$(G D D)$} \\
\hline Spotlight & $2959 c^{* * *}$ & $436 \mathrm{a} * * *$ & $2523 c^{* * *}$ & $211 a^{N S}$ & $229 b^{*}$ & $183 b^{* * *}$ & $464 \mathrm{a}^{\mathrm{NS}}$ & $445 b^{*}$ \\
\hline Diva & $3152 \mathrm{~b}$ & $272 b$ & $2880 \mathrm{~b}$ & $202 \mathrm{a}$ & 339 a & $266 \mathrm{a}$ & $526 \mathrm{a}$ & $754 \mathrm{a}$ \\
\hline Starlet & 3321 a & $297 \mathrm{~b}$ & $3024 \mathrm{a}$ & $206 \mathrm{a}$ & $237 \mathrm{~b}$ & $198 \mathrm{~b}$ & $596 \mathrm{a}$ & $578 \mathrm{ab}$ \\
\hline
\end{tabular}

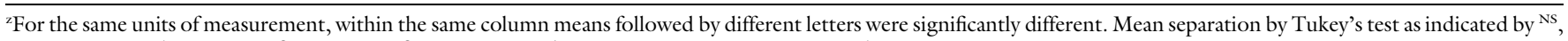
${ }^{*}, * *, * *$ are either not significant or significant at $P<0.05, P<0.01, P<0.0001$, respectively.

with 'Spotlight' requiring fewer days than both 'Diva' and 'Starlet'. When time was expressed as GDD, the same sequence of harvest maturity was observed (Table 1); 'Spotlight' required fewer GDD than either 'Diva' or 'Starlet'. GDD from the date of emergence to harvest was shortest for 'Spotlight', followed by 'Diva' and 'Starlet'.

The standard deviation of time (days) from the emergence of first shoots to harvest maturity was not significantly different among cultivars $(P>0.05$; Table 1$)$. It was different $(P<0.01)$ for time from shoot emergence to harvest, and the greatest variation was observed for time to harvest maturity of 'Diva'. As the standard deviation included outliers, which in a commercial situation might not be harvested, 10th to 90th percentile distribution in maturity dates might be more applicable for this analysis. With the outliers excluded from the analysis, the 10th to 90th percentile distribution detected more variability among cultivars than standard deviation, hence was used in most of the subsequent analyses.

There was no significant difference in the 10th to 90th percentile distribution of time (days) from the emergence of the first shoot to harvest maturity between 'Spotlight' and 'Diva', nor between 'Diva' and 'Starlet', but the 10th to 90th percentile distribution for 'Starlet' was greater than that for 'Spotlight' (Table 1). When the 10th to 90th percentile distribution was based on GDD, the time from emergence of the first shoot to harvest maturity was similar for each cultivar (Table 1 ). In contrast, the 10th to 90th percentile distribution for GDD from shoot emergence to harvest varied, with 'Diva' having a wider spread than 'Spotlight' and, based on days, the 10th to 90th percentile distribution observed in 'Diva' was greater than both 'Spotlight' and 'Starlet'.

Peak harvest maturity (i.e., median harvest date recorded as calendar days from the emergence of first shoot) was $184 \mathrm{~d}$ (mid-March) for 'Spotlight'; 204 d (early April) for 'Diva'; and $216 \mathrm{~d}$ (mid-April) for 'Starlet' (Fig. 2A). For both 'Spotlight' and 'Starlet', the spread in time of harvest maturity was skewed toward the latter part of the harvest period. For 'Spotlight', a 49-d spread from the median to the date of last harvest was apparent; 'Starlet' had a 44-d spread. By contrast, it was only 25 and $22 \mathrm{~d}$ from the first harvest date to the median date for 'Starlet' and 'Spotlight', respectively. The distribution of dates of harvest maturity for 'Diva' was not skewed, with $31 \mathrm{~d}$ from the first harvest date to the median, and $26 \mathrm{~d}$ from the median to the last harvest date (Fig. 2A).

Axillary shoots arose from nodes close to the proximal end of flowering shoots, giving the visual appearance of shoots arising separately from the crown. This was more prominent in 'Diva' than the other two cultivars. These axillary shoots were typically weak and short $(48 \mathrm{~cm})$ in 'Spotlight', but of commercial quality in 'Diva' $(84 \mathrm{~cm})$ and 'Starlet' $(60 \mathrm{~cm})$. Most of these axillary shoots flowered at the same time as the shoot to which they were attached and, therefore, did not contribute a separate source of variation in the timing of flowering shoots.

Time to SHOOT EMERgence. Shoot emergence in 'Spotlight' was significantly later than 'Diva' or 'Starlet', whether expressed as days or GDD (Table 1 ). The standard deviation of time to emergence was greater for 'Diva' than 'Starlet' or 'Spotlight'. Similarly, the 10th to 90th percentile distribution of GDD to shoot emergence for 'Diva' was about twice that for 'Starlet' and 'Spotlight' (Fig. 2B).

Correlations BeTWEen KeY VARIABLES. There was a stronger correlation between time to harvest maturity and time to emergence for 'Starlet' $\left(R^{2}=0.51\right)$, than 'Diva' $\left(R^{2}=0.33\right)$ or 'Spotlight' $\left(R^{2}=0.35\right)$ (Fig. 3A). The correlation was even stronger for 'Starlet' when determined using GDD $\left[R^{2}=0.7\right.$ (Fig. $\left.\left.3 \mathrm{~B}\right)\right]$. In contrast to the time to harvest, the time from emergence to harvest was negatively correlated with the date of emergence; later-emerging shoots reached harvest maturity more quickly than earlier-emerging shoots (Fig. 3C). This correlation was greatest in 'Diva' $\left(R^{2}=\right.$ $0.7)$. When the model was fitted using GDD, the negative relationship remained (Fig. 3C), although it was weaker, especially for 'Diva' $\left(R^{2}=0.54\right)$ and 'Spotlight' $\left(R^{2}=0.25\right)$. There were no correlations found between date of emergence and final shoot length 

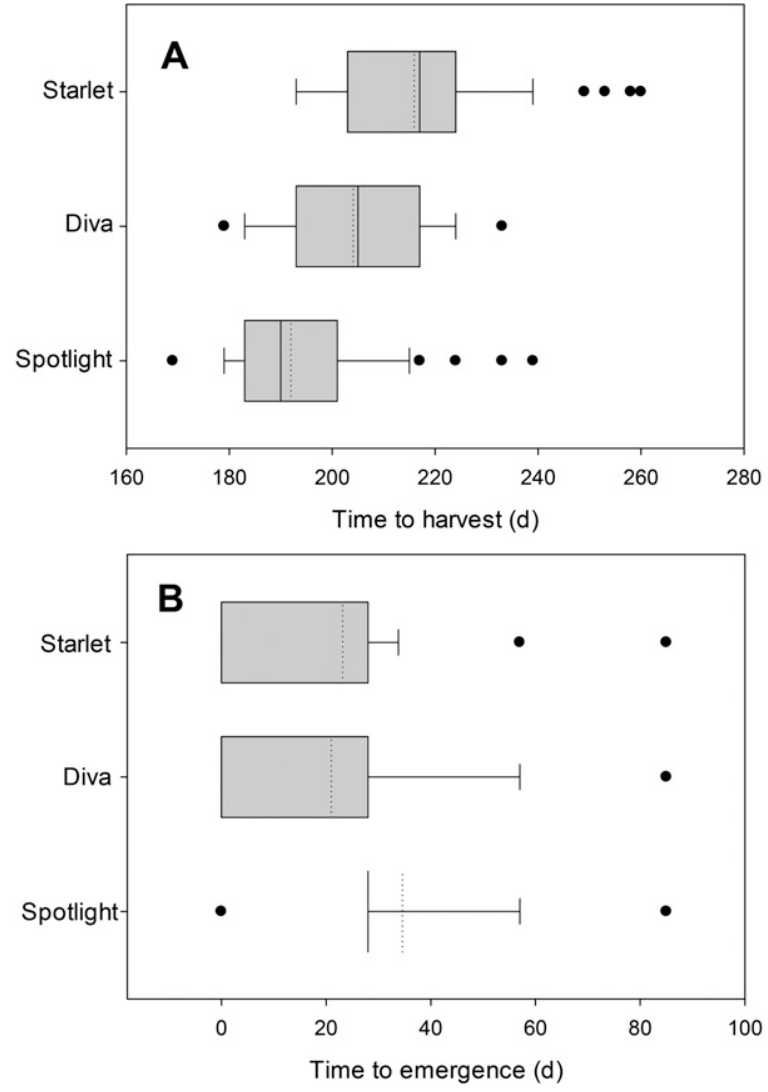

Fig. 2. (A) Time to harvest maturity among gentian cultivars [Showtime Spotlight $(n=123)$, Showtime Diva $(n=97)$, Showtime Starlet $(n=97)]$ or $(\mathrm{B})$ time to shoot emergence in calendar days. Solid and dashed vertical lines in the center of each box indicate the median and mean, respectively. Boundaries of box indicate 25 th and 75 th percentiles, whiskers indicate 10th and 90th percentiles, and solid dots indicate one or more individuals as outliers beyond these percentile limits.

('Diva' $R^{2}=0.01$; 'Spotlight' $R^{2}=$ 0.12 ; 'Starlet' $R^{2}=0.05$ ), or the date of harvest maturity and shoot length ('Diva' $R^{2}=0.01$; 'Spotlight' $R^{2}=0.08$; 'Starlet' $\left.R^{2}=0.07\right)$. Thus for 'Diva', although later-emerging shoots reach anthesis more quickly, this did not influence shoot length.

OUTLIERS IN TIME OF HARVEST MATURITY. In both 'Starlet' and 'Spotlight', there were outliers in time of harvest maturity beyond the 90th percentile occurring late in the season, but in 'Diva' most outliers were early and occurred before the 10th percentile (Fig. 2A). For 'Diva', 77\% of outliers ( 7 out of 9) reached harvest maturity at the beginning of the season, and $23 \%$ late in the season (after the 90th percentile). The outliers of 'Diva' that matured early developed from the first shoots to emerge, and the outliers that matured late all emerged after $57 \mathrm{~d}$. For 'Spotlight', only $20 \%$ of shoots classified as outliers flowered early with the remaining $80 \%$
(12 out of 15 shoots) emerging after $61 \mathrm{~d}$. In 'Starlet' all outliers (six) were late flowering, with an average time to shoot emergence of $75 \mathrm{~d}$. When compared with the average emergence time of all shoots, these extremely lateflowering outliers emerged later in the season. The average length of these late-flowering shoots was $82 \mathrm{~cm}$ in 'Diva', $76 \mathrm{~cm}$ in 'Spotlight', and $79 \mathrm{~cm}$ in 'Starlet'; these values were within the bounds of variation of the average shoot length for 'Diva' at $93 \pm 20 \mathrm{~cm}$ (mean \pm SD), 'Spotlight' at $84 \pm 9 \mathrm{~cm}$, and 'Starlet' at $75 \pm 10 \mathrm{~cm}$. Thus, shoot length does not appear to be influenced by date of shoot emergence.

\section{Spread in time of harvest maturity within cultivars}

Individual plants varied in their average time to harvest, with 'Spotlight' spread over $11 \mathrm{~d}$, 'Diva' $25 \mathrm{~d}$, and 'Starlet' $21 \mathrm{~d}$ (Table 2). There was more variation in time to emergence of 'Starlet' plants (31 d) than 'Diva' (12 d) or 'Spotlight' (13 d). By contrast, there was more variation in time from emergence to harvest in individual 'Spotlight' plants (17 d), than 'Starlet' or 'Diva' (Table 2). Similar patterns were apparent when GDD were used instead of calendar days (data not presented).

There was considerable variation between plants in their 10th to 90th percentile distribution of time to harvest maturity. In 'Spotlight', plant 3 took $16 \mathrm{~d}$ longer than plant 1 . In 'Diva', the maximum difference between individual plants was $14 \mathrm{~d}$ and, in 'Starlet', 9 d. 'Spotlight' had the highest number of outliers ( 15 shoots), and all replicates of 'Spotlight' had latematuring outliers, though four out of five plants also had early-maturing outliers. Only two of the replicates of 'Diva' had outliers, but there was still up to $25 \mathrm{~d}$ variation in average date of harvest maturity among individual plants. When compared with the other replicates, 'Starlet' plant 4 was late maturing. This was primarily because of outliers taking up to $260 \mathrm{~d}$ to mature, compared with an average of $215 \mathrm{~d}$ for the five replicate plants. Three of the replicate plants had outliers, the majority late flowering, which indicated greater among-plant variability in 'Starlet' than the other cultivars.

\section{Discussion}

Irrespective of whether expressed as calendar days or GDD, the three cultivars differed significantly in time to harvest (Table 1). Correlations were evident between time to shoot emergence and the time to reach harvest maturity, and time to shoot emergence and the time from emergence to harvest maturity, in all cultivars (Fig. 3). There is little published research into correlations between time to shoot emergence and time to harvest; however, similar to our study, a positive correlation was reported between time to shoot emergence and flowering in spring pea [Lathyrus vernus (Sola and Ehrlen, 2006)]. The negative relationship observed between time to shoot emergence and time from emergence to harvest maturity for the three cultivars was unexpected. Our finding that late-emerging shoots reach harvest maturity earlier is at odds with the more commonly reported positive relationship observed in, for example, African blood lily 

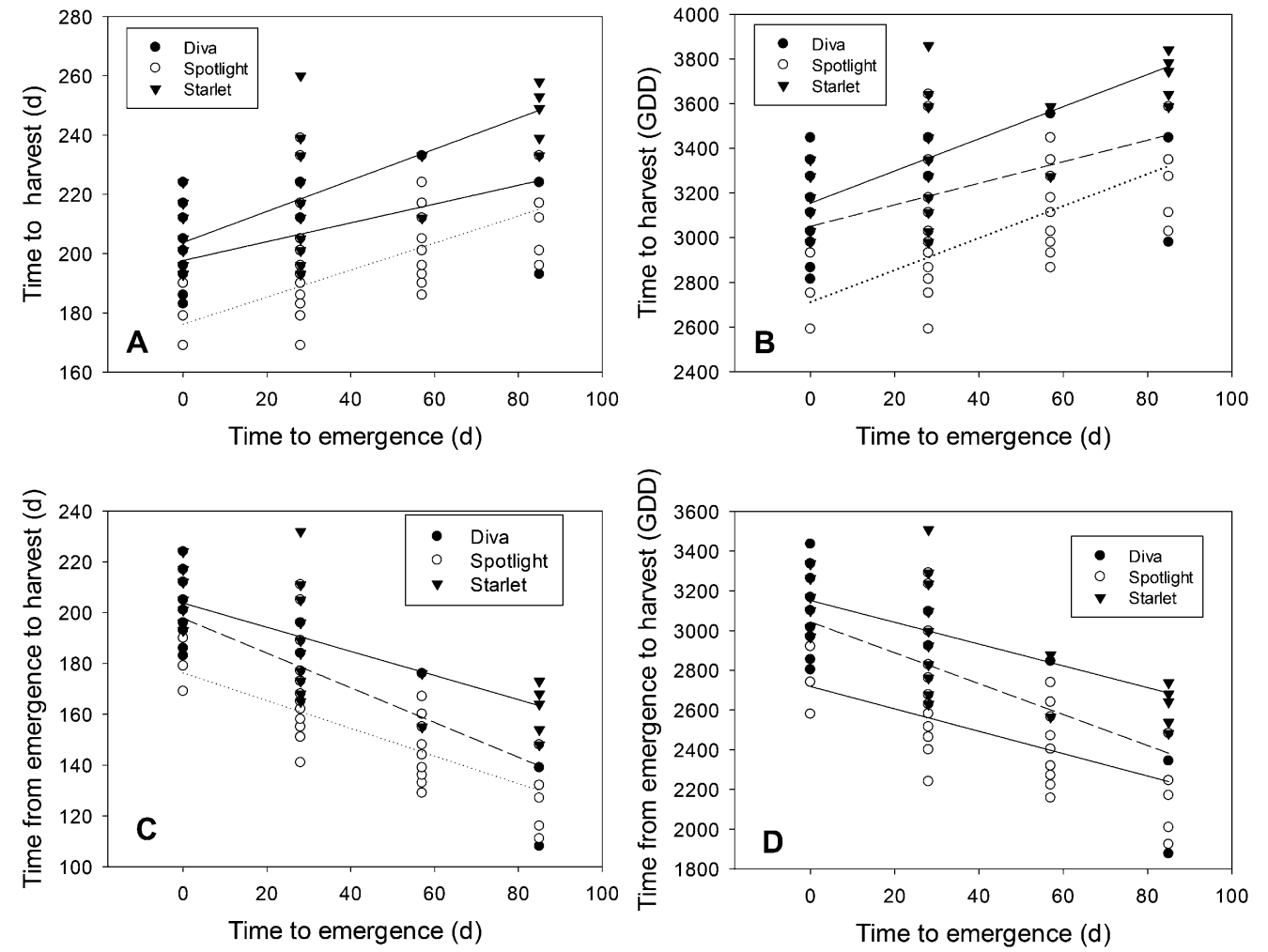

Fig. 3. (A) Correlation between time to gentian shoot emergence and time to harvest ['Showtime Diva' $(-), R^{2}=0.33$; 'Showtime Spotlight' (...), $R^{2}=\mathbf{0 . 3 5}$; 'Showtime Starlet' $\left.(-), R^{2}=0.51\right]$. (B) Growing degree-days [GDD base temperature $0{ }^{\circ} \mathrm{C}\left(32.0{ }^{\circ} \mathrm{F}\right)$ ] to shoot emergence and time to harvest ['Showtime Diva' $\left(R^{2}=0.33\right)$, 'Showtime Spotlight' $\left(R^{2}=0.35\right)$, 'Showtime Starlet' $\left.\left(R^{2}=0.70\right)\right]$. (C) Time to shoot emergence and time to harvest from shoot emergence ['Showtime Diva' $\left(R^{2}=0.70\right)$, 'Showtime Spotlight' $\left(R^{2}=0.43\right)$, 'Showtime Starlet' $\left.\left(R^{2}=0.45\right)\right]$. (D) GDD to shoot emergence and from shoot emergence to harvest ['Showtime Diva' $\left(R^{2}=0.54\right)$, 'Showtime Spotlight' $\left(R^{2}=0.25\right)$, 'Showtime Starlet' $\left(R^{2}=0.35\right)$ ]. Regression correlations were significant at $P<0.0001$.

[Scadoxus multiflorus(Funnell, 2008)]. This may be partly explained by acknowledging that the influence of time of shoot emergence on time of harvest depended on cultivar, and its effect seemed greater in the latest flowering cultivar, Starlet. In 'Starlet', shoot maturity was likely further delayed by cooler temperatures later in the season (Fig. 1). 'Diva', although later flowering than 'Spotlight', had more rapid shoot development, resulting in a shorter time to harvest in lateemerged shoots. 'Diva' is, therefore, hypothesized to be less affected by cooler temperatures in terms of time to reach harvest maturity.

Under the temperature range experienced during the experiment (Fig. 1), GDD models did not improve the strength of the correlation in determining time to harvest for all the cultivars. For this study we assumed a base temperature of $0{ }^{\circ} \mathrm{C}$. As reported for other species, base temperatures can vary according to developmental stage (Funnell, 2008) and cultivar
(Bell et al., 1991). A differential response to temperature in development to harvest maturity has been reported in gentians, in which early cultivars flowered earlier at higher temperatures $\left(20-25^{\circ} \mathrm{C}\right)$ than late cultivars, in which flowering was delayed at this same temperature range (Ohkawa, 1983). Thus in the current study, the lack of specific information regarding base and optimum temperatures for growth and development for the cultivars used may have limited the information derived using GDD. Additionally, there is some evidence that time to harvest in late-flowering cultivars is influenced by short days (Ohkawa, 1983). Hence, an influence of declining daylength may be embedded in the temperature response of time to harvest.

'Spotlight' had a narrower spread in the time from emergence to harvest than the two later-maturing cultivars (Table 1). Time of emergence was also more even than the other cultivars, i.e., a smaller spread. In 'Spotlight', variation among plants was most evident after emergence. As indicated by the presence of many outliers, variability in maturation of shoots within individual plants was greater in 'Spotlight' than the other cultivars. Hence, if in the future narrowing down of the spread in harvest maturity is required in 'Spotlight', it will be important to control the occurrence of such influential outliers.

'Starlet' presented the widest 10th to 90th percentile distribution (Table 1), and also the greatest plantto-plant variability in time to harvest (Table 2). Since shoot emergence was compact in 'Starlet', it is suggested that declining temperatures in the fall (Fig. 1) can at least partially account for the spread. However, the spread and variation among plants was not because of the variability in time from shoot emergence to harvest, but because of the variation in time to shoot emergence (Table 2). Hence, in 'Starlet' it is hypothesized that to manipulate the spread, the determinants of these 
Table 2. Average time to harvest maturity, shoot emergence, and from emergence to harvest maturity, in calendar days for individual plants within each of three cultivars of gentian (Showtime Spotlight, Showtime Diva, and Showtime Starlet).

\begin{tabular}{|c|c|c|c|c|c|c|c|c|c|}
\hline \multirow{2}{*}{$\begin{array}{l}\text { Plant } \\
\text { number }\end{array}$} & \multicolumn{3}{|c|}{ Time to harvest maturity $(d)^{\mathrm{z}}$} & \multicolumn{3}{|c|}{ Time from emergence to harvest maturity (d) } & \multicolumn{3}{|c|}{ Time to emergence $(\mathrm{d})$} \\
\hline & Spotlight* * $^{*}$ & Diva* & Starlet $^{* * *}$ & Spotlight*** & Diva $^{\text {NS }}$ & Starlet $^{\mathrm{NS}}$ & Spotlight $^{\text {NS }}$ & Diva $^{\text {NS }}$ & Starlet*** \\
\hline 1 & $188 \mathrm{~b}$ & 219 a & $218 \mathrm{ab}$ & $148 \mathrm{~b}$ & 196 & 195 & $40 \mathrm{a}$ & $23 \mathrm{a}$ & $22 \mathrm{ab}$ \\
\hline 2 & $188 \mathrm{~b}$ & $206 \mathrm{bc}$ & $211 \mathrm{bc}$ & $153 \mathrm{~b}$ & 181 & 198 & $35 \mathrm{a}$ & $25 \mathrm{a}$ & $13 \mathrm{~b}$ \\
\hline 3 & $191 \mathrm{~b}$ & $199 \mathrm{~cd}$ & $205 \mathrm{c}$ & $156 \mathrm{~b}$ & 185 & 196 & $27 \mathrm{a}$ & $15 a$ & $09 \mathrm{~b}$ \\
\hline 4 & $191 \mathrm{~b}$ & $194 \mathrm{~d}$ & $226 \mathrm{a}$ & $165 \mathrm{a}$ & 178 & 186 & $34 \mathrm{a}$ & $18 \mathrm{a}$ & $40 \mathrm{a}$ \\
\hline 5 & $199 \mathrm{a}$ & $210 \mathrm{~b}$ & $212 b c$ & $165 \mathrm{a}$ & 183 & 191 & $35 \mathrm{a}$ & $26 a$ & $21 \mathrm{~b}$ \\
\hline
\end{tabular}

${ }^{2}$ Within the same column, means followed by different letters are significantly different. Mean separation by Tukey's test as indicated by ${ }^{\text {Ns }}$ * * * ** are either not significant or significant at $P<0.05, P<0.01$, and $P<0.0001$, respectively.

two aspects need to be understood in more detail. Physiological or environmental stimuli involved in the induction or breaking of bud dormancy have not been documented for gentians, but chilling to break endodormancy has been inferred (Ohkawa, 1983). Once the requirement for chilling has been met, uniform shoot emergence is enabled (Lang et al., 1987), but paradormancy and ecodormancy could also influence the development of buds simultaneously or separately (Horvath et al., 2003). Future investigations with 'Starlet' would, therefore, benefit from investigating the influence paradormancy, endodormancy, and/or ecodormancy have in time of shoot emergence, as well as the influence of temperature and daylength during shoot development.

'Diva' was relatively late flowering, and had a wider spread in both time to shoot emergence and time from emergence to harvest (Table 1). As evident by the failure of GDD to alter the correlations between the variables that determined the time to harvest (Fig. 3), no response was detected in extending the time to harvest maturity with respect to the declining temperatures during the late season (Fig. 1). Spread in time to harvest maturity was similar in 'Diva' and 'Starlet', but the spread in time to harvest from emergence, as well as time to emergence, was widest in 'Diva' (Fig. 2). The observed wide spread in time to harvest from emergence was due to the shoots taking varying times to reach harvest maturity, based on date of emergence (Fig. 3). Less variability in harvesting dates may, therefore, be due to a greater ability of shoots within 'Diva' to reach harvest maturity at a comparatively uniform time, irrespective of the date of shoot emergence (Fig. 3). Hence, as observed in populations of gorse [Ulex europaeus (Tarayre et al., 2007)],
'Diva' appears to display greater phenotypic plasticity in reaching harvest maturity than the other cultivars. With 'Diva', we hypothesize that the primary source of spread arises from changes in the time to emergence of individual shoots. Once emerged, shoots reach harvest maturity relatively uniformly.

Axillary shoots, which appear to arise as individual shoots, flowered at the same time as the main shoot to which they were attached. Thus in a commercial context, these axillary shoots are unlikely to be a source of variation in time of harvest maturity.

Shoots that matured early, and were categorized as outliers, were prominent in 'Diva', and matured late in 'Starlet' and 'Spotlight'. All these shoots were of marketable quality. If we consider the average frequency of late outliers for 'Spotlight' (i.e., 0.096 shoots per plant per day) and assume a between plant spacing of $20 \times 20 \mathrm{~cm}$ (Hubber, 1994), to collect 100 shoots the harvester would have to walk $208 \mathrm{~m}$ of bed. During the peak of the flowering season (i.e., between the 25 th and 75 th percentiles), 100 shoots can be picked within $31 \mathrm{~m}$ of bed. This knowledge allows growers to now consider potential differences in economic returns between these two harvesting periods. Although it is desirable to manage the earliness or lateness of outliers, the causes of the observed variation in flowering time of individual shoots, outliers or otherwise, on an individual plant, require further investigation.

\section{Conclusion}

Gentians show different degrees of variability in time of harvest maturity among cultivars, among plants of the same cultivar, and among shoots within a plant. The spread in time of harvest maturity, as well as the factors contributing to the spread in harvest maturity dates of these clonally propagated plants, appears specific to individual gentian cultivars. For commercial cultivars, reasons for the variation in time of harvest maturity will need to be investigated by exploring how plant and/or environmental factors influence the growth and development of individual buds/shoots within a plant, from bud initiation to harvest maturity.

\section{Literature cited}

Arnold, C.Y. 1959. The determination and significance of the base temperature in a linear heat unit system. Proc. Amer. Soc. Hort. Sci. 74:430-445.

Bell, M.J., R. Shorter, and R. Mayer. 1991. Cultivar and environmental effects on growth and development of peanuts (Arachis hypogaea L.). I. Emergence and flowering. Field Crops Res. 27:17-33.

Eason, J.R., E.R. Morgan, A.C. Mullan, and G.K. Burge. 2004. Display life of Gentiana flowers is cultivar specific and influenced by sucrose, gibberellin, fluoride, and postharvest storage. N. Z. J. Crop Hort. Sci. 32:217-226.

Fisher, P.R., R.D. Heins, and J.H. Lieth. 1998. Predicting variability in anthesis of easter lily (Lilium longiflorum Thunb.) populations in response to temperature. Acta Hort. 456:117-124.

Funnell, K.A. 2008. Growing degree-day requirements for scheduling flowering of Scadoxus multiflorus subsp. katharinae (Baker) Friis \& Nordal. HortScience 43: 166-169.

Funnell, K.A., M. Bendall, W.F. Fountain, and E.R. Morgan. 2003. Maturity and type of cutting influences flower yield, flowering time, and quality in Limonium 'Chorus Magenta' N. Z. J. Crop Hort. Sci. 31:139-146.

Horvath, D.P., J.V. Anderson, W.S. Chao, and M.E. Foley. 2003. Knowing when to grow: Signals regulating bud dormancy. Trends Plant Sci. 8:534540 . 
Hubber, N. 1994. Cool climate flowers: A beginner's guide to commercial bulb growing in southern New Zealand. Craig Printing, Invercargill, New Zealand.

Lang, G.A., J.D. Early, G.C. Martin, and R.L. Darnell. 1987. Endo-, para-, and ecodormancy: Physiological terminology and classification for dormancy research. HortScience 22:371-377.

Massey University. n.d. Manawatu fine sandy loam. 10 July 2013. <http://atlas.massey. ac.nz/soils/profiles/profile.html?P54>.
Ohkawa, K. 1983. Gentiana, p. 351-355. In: A.H. Halevy (ed.). CRC handbook of flowering. CRC Press, Boca Raton, FL.

Samarakoon, U.C., K.A. Funnell, D.J. Woolley, G.K. Burge, and E.R. Morgan. 2012. Crown buds in gentians: Appearance, shoot emergence and development. Acta Hort. 937:483-490.

Sola, A.J. and J. Ehrlen. 2006. Vegetative phenology constrains the onset of flowering in the perennial herb Lathyrus vernus. J. Ecol. 95:208-216.

Tarayre, M., G. Bowman, A. SchermannLegionnet, M. Barat, and A. Atlan. 2007. Flowering phenology of Ulex europaeus: Ecological consequences of variation within and among populations. Evol. Ecol. 21:395-409. 